\title{
Cristina Bautista Taquinás Mujer indígena Nasa, Trabajadora Social, lideresa del norte del Cauca, Colombia ${ }^{1}$
}

\author{
Alba Nubia Rodríguez-Pizarro \\ Antropóloga. Doctora en Ciencias Políticas \\ Universidad del Valle. Cali, Colombia \\ https:// orcid.org/0000-0003-1055-9636 • alba.rodriguez@correounivalle.edu.co \\ Lady Johanna Betancourt-Maldonado \\ Trabajadora social. Magister en Psicología \\ Universidad del Valle. Cali, Colombia \\ https:/ / orcid.org/0000-0001-9414-8601 • lady.betancourt@correounivalle.edu.co
}

Si nos quedamos callados nos matan, y si hablamos también

(La verdad nada más que la verdad, 2019).

La barbarie se ensaña contra los nasas Desde Toribío hasta Tacueyó hay cuatro retenes del pueblo nasa; y otro más entre Tacueyó y la vereda La Capilla, hacia donde se dirigía la gobernadora indígena Cristina Bautista Taquinás el miércoles en la tarde. Ella y cuatro de sus compañeros cayeron muertos en medio de una carretera polvorienta. Cinco más quedaron heridos. Los detuvieron, les impidieron el paso, los

bajaron de los vehículos y les dispararon a sangre fría. Las imágenes de cómo quedó la camioneta, llena de tiros, revelan la crueldad de lo ocurrido. Al día siguiente, cientos de indígenas acompañaron su despedida, en medio de gritos y lamentos.

(Semana, 2019)

1 La semblanza que presentamos fue posible realizarla gracias a la participación y narración de la familia de Cristina: su madre, padre, hermanas y hermano. Gracias también a su amiga y compañera de lucha Yoli, integrante del movimiento Hilando pensamiento, quien quiso honrar la memoria, no solo de su amiga sino de la mujer y la autoridad Nasa. Sus relatos contribuyeron de manera fundamental para lograr este escrito que hoy presentamos, en homenaje a la mujer indígena, lideresa, profesional y egresada de la Escuela Trabajo Social y Desarrollo Humano de la Universidad del Valle.

c) (i) (-) Esta obra está bajo una Licencia Creative Commons Atribución-NoComercial-CompartirIgual 4.0 Internacional.

¿Cómo citar este artículo? / How to quote this article?

Rodríguez-Pizarro, A.N., y Betancourt-Maldonado, L.J. (2020). Cristina Bautista Taquinás. Mujer indígena Nasa, Trabajadora Social, lideresa del norte del Cauca, Colombia. Prospectiva. Revista de Trabajo Social e intervención social, (30), 309-319. doi: 10.25100/ prts.v0i30.10178. 


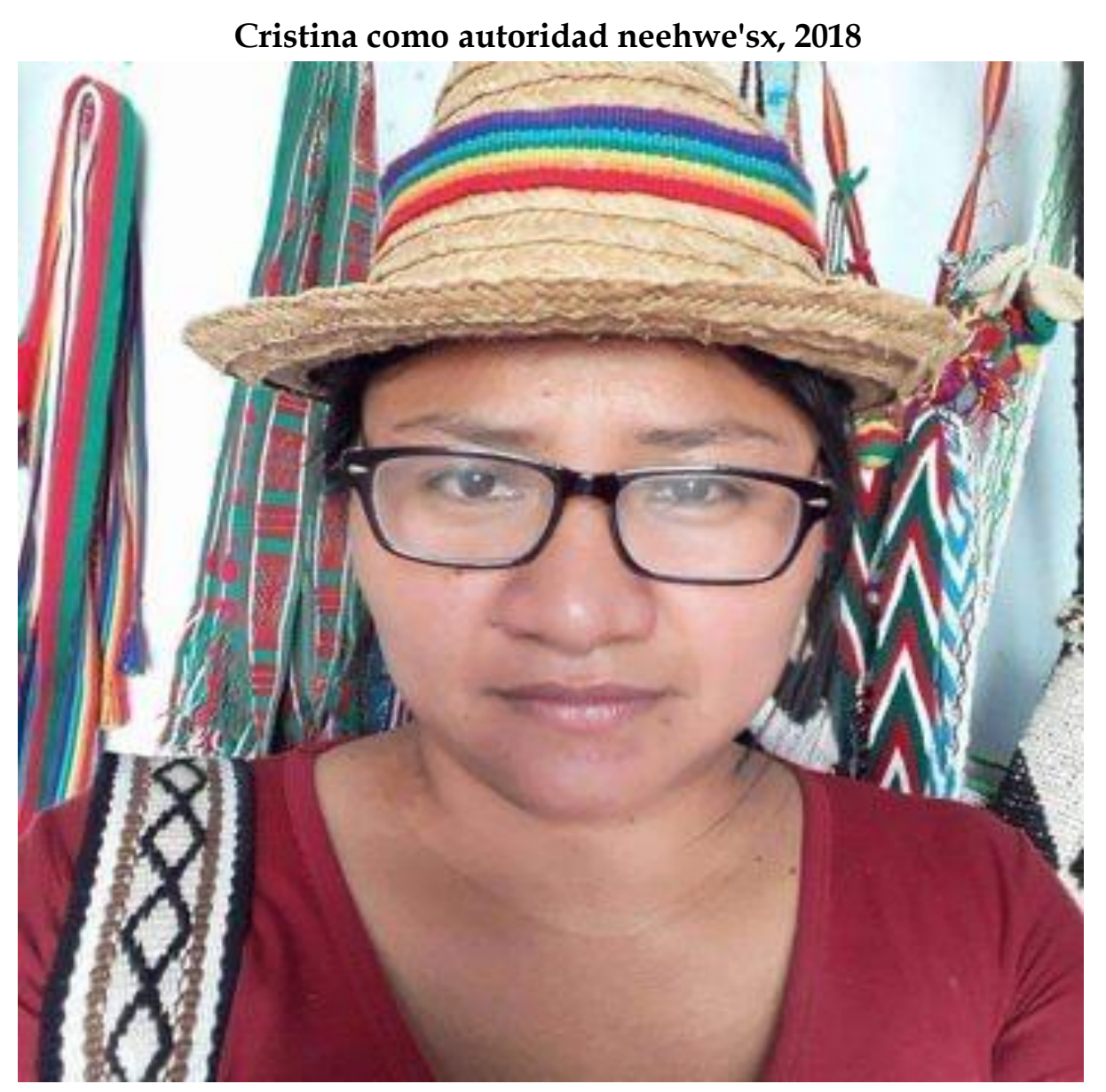

Fuente: DesInformémonos, 2019.

El 29 de octubre en horas de la tarde, los medios de comunicación informaban sobre cómo la barbarie llegaba de nuevo al Departamento del Cauca y específicamente a la vereda La Luz del municipio de Toribío. Esta vez informaron sobre la masacre ocurrida en horas de la tarde de ese martes de octubre. Asesinaron a cinco personas integrantes del pueblo Nasa, entre ellos la Trabajadora Social y Gobernadora Indígena, Cristina Bautista Taquinás, de 30 años de edad, quien regresó a su comunidad y al resguardo de Tacueyóen Toribío, después de haber tenido que salir de su pueblo a la edad de 12 años a trabajar en labores domésticas en casas en Corinto y en Cali, para subsistir y así cumplir con uno de sus mayores sueños: estudiar para obtener su título de bachiller y posteriormente entrar a la Universidad del Valle. Es decir, comenzar a construir la trayectoria de vida de una mujer como se construyen algunas, desde los márgenes, desde la periferia y anteponiéndose a la exclusión, a la marginalidad y al no reconocimiento.

Cristina retornó a su comunidad, movida por el principio de retribuir a su pueblo lo aprendido; inicialmente su voz no provocó mucho eco, por más que intentaba e incursionaba en los procesos comunitarios, su voz no era escuchada. No obstante, desde 
Rodríguez-Pizarro y Betancourt-Maldonado

sus convicciones, humildad y perseverancia, que aprendió desde niña, comenzó a conversar con algunas mujeres para conformar un proceso colectivo y contribuir con la organización de mujeres Nasa, para luchar por los derechos de ella y de otras, a través del movimiento Hilando Pensamiento. Nuevamente inicia, una vez más, la construcción de su trayectoria, la historia de Cristina desde "el margen", trazando un camino que tal vez poco se conoce pero que sin duda ha aportado a la construcción cultural del pueblo Nasa en el norte del Cauca y en el sur del continente, como también a la construcción de poder, entendido como la creación, el fortalecimiento de nuevas relaciones y nuevas realidades.

Para el logro del reconocimiento era necesario trabajar con las mujeres, con los hombres, con los niños y las niñas. Si bien hoy es recordada, reconocida y valorada por su lucha por los derechos de las mujeres y los derechos de su pueblo y como autoridad de su cabildo, esto no siempre fue así, porque cuando la lideresa indígena empezó el trabajo con su comunidad y con las mujeres, después de obtener su título universitario, Cristina fue cuestionada por algunos integrantes de su pueblo, por ser mujer y por sus creencias religiosas que nunca impuso a su pueblo, como lo afirma Yoli, actual integrante del movimiento Hilando Pensamiento. No obstante, con su sabiduría, humildad y compromiso, logró el reconocimiento de su comunidad y de su familia conformada por madre, padre, tres hermanas, un hermano, cuatro sobrinas y un sobrino que permanecen y subsisten en la vereda La Capilla del municipio de Toribío.

En el mes de junio de 2019 fue elegida por su comunidad como autoridad neehwe'sx, del resguardo de Tacueyó. Como lideresa planteó a su pueblola necesidad de mantenerse en resistencia ante los actores armados y exigir la implementación de los Acuerdos de paz con las Farc, no permitir y resistir ante la presencia de actores armados que actualmente hacen presencia en el territorio. Es así como hoy las mujeres quieren que su legado y su palabra perduren.

\section{La Familia de Cristina...Cómo se constituye una lideresa entre la resistencia y el desarraigo}

Cristina nació en la vereda La Capilla en una familia conformada por una pareja de jóvenesNasa, la mamá de 16 años y el papá de 18 años, quienes tuvieron cinco hijos. Cristina, la hija mayor, nació en la casa de los abuelos paternos, donde también vivía la bisabuela, persona muy significativa para Cristina. Desde muy niña asumió la responsabilidad y el cuidado de sus hermanos menores para que su madre se fuera a trabajar y obtener algunos recursos para la subsistencia, dado que eran "una familia muy pobre"; así lo narra la madre. Pese a que se identifican como Nasas no hablan el Nasa Yuwe y tampoco lo enseñaron a sus hijas e hijo, porque durante la niñez en la escuela se burlaban de quienes hablaban su lengua. 
Rodríguez-Pizarro y Betancourt-Maldonado

\section{Cristina a la edad de dos años, Toribío, Cauca}

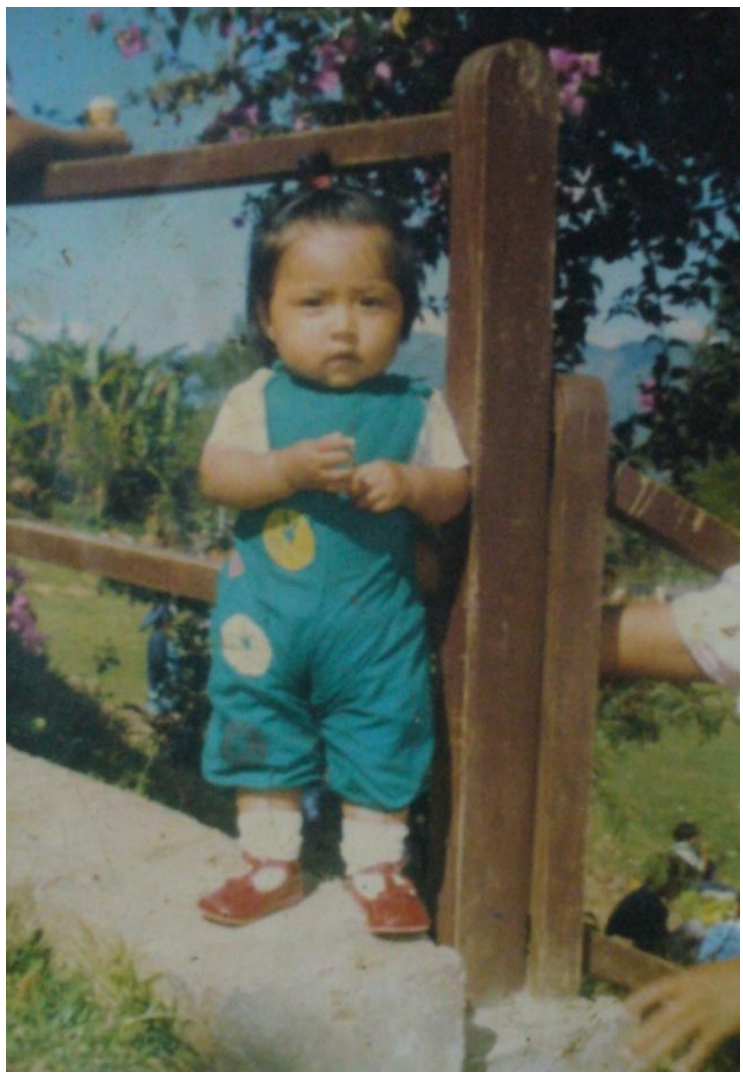

Fuente: álbum familiar

La madre recuerda a Cristina como "una niña muy trabajadora que tuvo una niñez muy difícil". A la edad de seis años, asumió gran parte del cuidado de sus hermanas y hermano, como llevarlos a la guardería antes de irse para la Escuela, y después de que salía lavaba la ropay cocinaba para toda la familia. Cuando estaba en quinto de primaria decidió salirse de la Escuela porque le pidieron media libra de arroz y la familia no tenía cómo comprarla y por eso prefirió dejar la Escuela, para no incumplir.

A ella como hermana mayor le tocó muy duro (...) yo le puse mucha responsabilidad. Yo los tuve a todos iguales, con uno, dos años, se llevan poquito, yo nunca planifiqué, en ese tiempo no se hablaba de planificar (...), en ese tiempo yo era muy joven y nadie me dijo nada, yo los tuve a todos igualitos y la situación económica era muy dura, yo tenía que salir a coger café todo el día, entonces le decía "vaya pa' la escuela y llévelos a la guardería, a ella le tocaba uno en la espalda y los otros en las manos. Y ella así lo hacía, bajaba nuevamente de la escuela, los cargaba y llegaba a cocinar, a lavarles la ropa, mientras yo llegaba del trabajo a hacer lo demás. (Mamá de Cristina).

De acuerdo con el relato de la madre,Cristina se rebuscaba trabajando en fincas de su vereda cocinando para trabajadores. Cuando tenía doce años decidieron que se fuera a trabajar a Corinto en una casa de familia, donde le tocaba muy duro porque el señor 
Rodríguez-Pizarro y Betancourt-Maldonado

trabajaba en corte de caña y ella tenía que lavarle la ropa. En Corinto comenzó a asistir a la Iglesia Pentecostal y allá conoció a otra persona que le ofreció un trabajo como ayudante de costura, y en un año aprendió a coser y cuando visitaba a la familia les traía faldas y vestidos a sus hermanas.

A los 13 años, una prima la llevó a Cali a trabajar en una casa y estando ahí, el señor de aquella familia llegó borracho e intentó violarla. De esa casa se voló y llamó a la prima para contarle lo sucedido y decirle que estaba en la calle. La prima la recibió y le buscó otro trabajo en una casa donde le tocaba cocinar y hacer todos los oficios domésticos. La mamá le decía que regresara con su familia a Toribío, pero ella no queríavolver hasta tanto no juntara el dinero para comprar una máquina de coser.

En la iglesia conoció a una señora que le ofreció otro trabajo y, estando allí, reunió un millón de pesos y los envió al papá para que le comprara un ternero. La señora le dijo que ella debía seguir estudiando y fue a un colegio en Cali para que Cristina continuara, pero le pidieron el certificado de quinto de primaria y ella no lo había terminado, aun así le hicieron una prueba y pudo entrar la Colegio Santa Librada a estudiar el bachillerato. Cuando terminó y se graduó, invitó a la familia a celebrar, ninguno conocía Cali, fue la primera vez que visitaron la ciudad, porque además sentían mucho miedo de la cantidad de gente, las calles, los carros y todo lo desconocido que implicaba la ciudad.

Cristina en su grado de Bachiller, junto a su madre, padre, hermana, una docente y otra compañera.

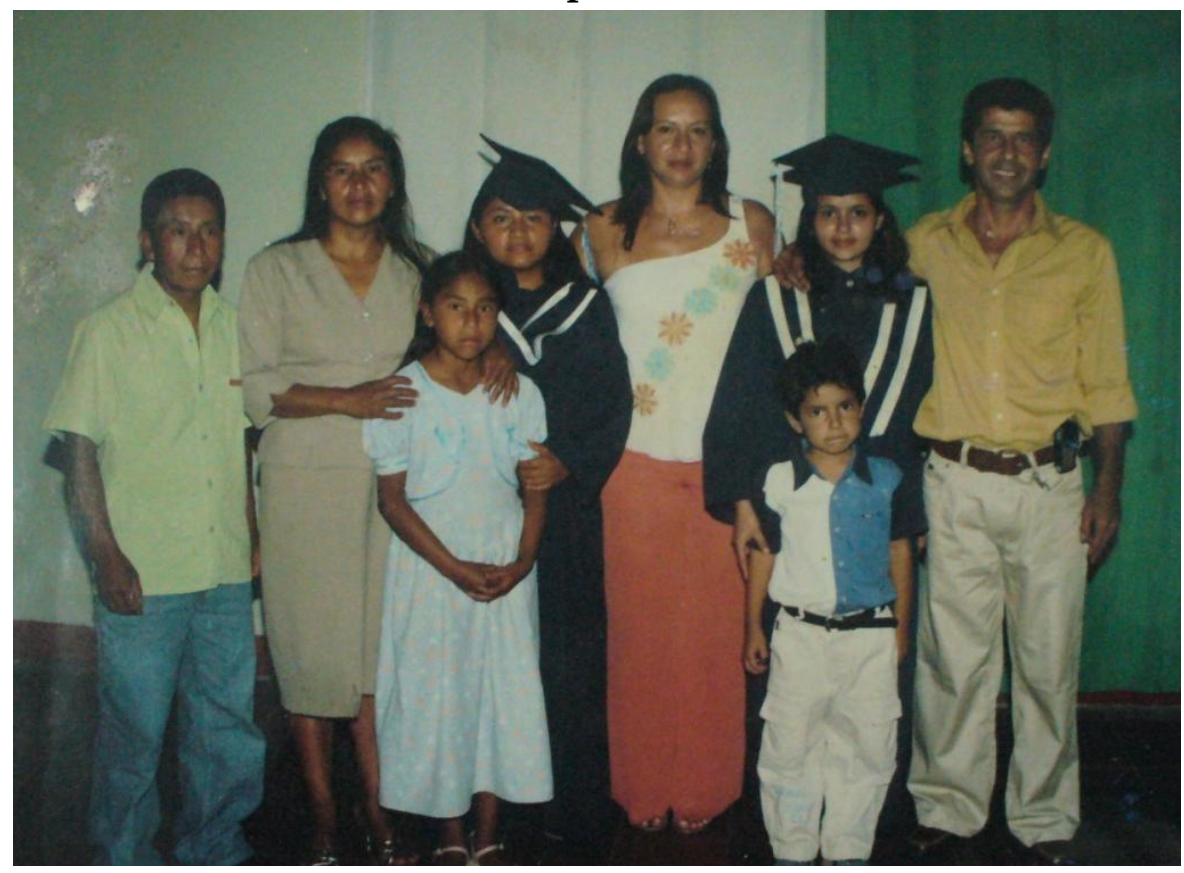

Fuente: álbum familiar 
Rodríguez-Pizarro y Betancourt-Maldonado

Después de su grado de bachiller,Cristina decidió entrar a la universidad y consiguió "una piecita" para vivir; el papá trabajaba y le ayudaba para el transporte y para el pago de la habitación. Ingresó a la Universidad del Valle a estudiar Terapia Ocupacional. Cristina seguía luchando para conseguir los recursos para subsistir en la ciudad.Trabajó vendiendo jugos de naranja en los alrededores de lasCanchas Panamericanas de la ciudad de Cali, las naranjas se las enviaban de Tacueyó. Lo que se ganaba le alcanzaba para subsistir, ante la situación, la mamá vino a Cali a vivir con ella para ayudarle con la venta de jugos. Después vendió cholados en un puesto cerca de las Canchas Panamericanas. Estando ahí, un vendedor de la zona le dijo que tenía que irse y puso la queja en la Secretaría de Salud, por lo cual le quitaron el puesto y todo lo que ella tenía. En ese momento,al quedar sin medios para subsistir en una ciudad inhóspita entre muchas personas para quien ella y su lucha e historia eran desconocidas, cayó en bajo rendimiento académico en la Universidad. Pasado un tiempo, después de perderlo todo, pero sin sentirse derrotada y agotando muchos trámites,las autoridades le devolvieron algunas cosas del puesto de venta de cholados, pero no pudo continuar con el expendio. Nuevamente la familia le dijo que volviera a la casa, que su papá no le ayudaría más, y ella nuevamente no consideró el regreso. Continuó en Cali, incluso aguantando hambre, relata su madre, y decidió presentarse al Programa de Trabajo Social para continuar su formación, y así lo hizo, lo único que comía en el día era el almuerzo que en la Universidad del Valle le suministran al estudiantado.

La mamá de Cristina narra que prestaba plata para ayudarle, pero la situación era muy difícil, hasta que tomó la decisión de viajar a Cali a trabajar en oficios domésticos para apoyar a su hija quien en ese momento no tenía dónde vivir. Una señora conocida la había dejado quedarse en su casa mientras conseguía trabajo. La mamá tampoco conseguía empleo en casas de familia porque no tenía experiencia. Después de un tiempo logró ubicarse en una casa y consiguieron una pieza donde vivían juntas y continuaban trabajando en oficios domésticos. Posteriormente, la madre retorna a Toribío y Cristina encuentra trabajo como ayudante en preparación y ventas de comida rápida; tiempo después, tuvo la posibilidad de desempeñarse como Monitora en la parte administrativa de la Universidad y allí,en palabras de su mamá, "se le recompuso la situación" y pudo terminar de estudiar.

\section{Su vida en la Universidad: entre la lucha por la subsistencia y la contribución a su pueblo}

Cristina soñó con estudiar y llegar a la Universidad, desde niña no dudó en trabajar en oficios domésticos en casas para conseguir los recursos para lograrlo. Con este sueño migró de su vereda La Capilla, dejando a su familia para terminar el bachillerato y llegar en dos ocasiones a la Universidad del Valle. 
Rodríguez-Pizarro y Betancourt-Maldonado

En la Escuela de Trabajo Social la recordamos como una estudiante inteligente, con un gran deseo de aprender y "hacer las cosas bien". Cuando llegó a Trabajo Social le gustó mucho el contenido de las asignaturas, comentaba que era lo que ella siempre había soñado, se esforzaba por tener un rendimiento académico adecuado, pese a las dificultades que sorteaba para subsistir.

Cristina prestaba especial interés a las asignaturas que le brindaban herramientas para el trabajo comunitario, los diagnósticos participativos, la producción de conocimientoy la comprensión de fenómenos, como la violencia hacia los niños, las niñas y las mujeres, para así proponer procesos de intervención adecuados que permitieran contribuir a resolver problemas y atender necesidades de su comunidad y en su territorio. Se destacó como una estudiante entusiasta y participativa en las clases, que construía buenas relaciones con sus compañeras/os y profesoras/es. Siempre estaba interesada en los procesos de transformación social, en el logro de la realización de los Derechos Humanos, en la construcción de una sociedad con mayor justicia, reconocimiento e igualdad social.

En la medida que avanzó semestre tras semestre, en los distintos cursos ganó el reconocimiento y afecto de sus compañeros/as y profesores/as, por ser una mujer que no se destacaba por sus pretensiones, sino por sus acciones, por sus luchas, su coherencia y su entusiasmo. Su estadía en la Universidad también fue difícil, como lo puede ser para cualquier estudiante que provenga de las zonas rurales del país, en las que la educación recibida previamente no se ajusta a los cánones de exigencia de una institución de educación superior. De esta manera, no sólo algunos estudiantes deben aprender y formarse en una disciplina específica, sino que es necesario transitar por los aprendizajes del manejo adecuado del idioma, de las lógicas relacionales, en las que en ocasiones impera la exclusión por género y pertenencia étnico-racial. Cristina no fue ajena a estos duros desafíos.

En sexto semestre, Cristina y una compañera comenzaron a perfilar su tema de trabajo de grado, el cual daba cuenta de su continua preocupación por los impactos del conflicto armado, en el que no dejó de ser su territorio, el municipio de Toribío del departamento del Cauca. Así, se interesaron por:

conocer y 'dar a conocer', cómo ha sido el proceso de reparación integral al que tienen derecho estas comunidades por el daño físico, mental, emocional, cultural y material que han sufrido cada uno de sus miembros de forma tanto individual como colectiva. (Bautista-Taquinas y Hernández-Mestizo, 2018, p. 4). 
Rodríguez-Pizarro y Betancourt-Maldonado

De esta manera, Cristina y su compañera de monografía Danna Hernández,se decidieron por estudiar los procesos de reparación a las víctimas del conflicto armado y propusieron la pregunta:

¿Cuál es el proceso de implementación de la Ley 1448 del 10 de junio de 2011, y el Decreto Ley 4633 del 9 de diciembre de 2011 por la Unidad de Víctimas del Departamento del Cauca y la Alcaldía del municipio de Toribio con familiares víctimas de homicidio en el conflicto armado y las percepciones que éstos han construido sobre la atención suministrada por las instituciones locales y regionales para la reparación entre los años 2005 al 2016?(Bautista-Taquinas y Hernández-Mestizo, 2018 p. 9)

Tema e interrogante premonitorio de lo que sucedería dos años después con el asesinato de Cristina, el 29 de octubre de 2019, casiun año después de haber obtenido el título de Trabajadora Social. Una víctima más de los actores violentos que disputan su territorio, sin que hasta la fecha se haya hecho justicia, ni reparado a la familia por su asesinato, ni se haya vencido la impunidad.

Cristina en su grado de Trabajadora Social, junto a su madre y padre, 2018

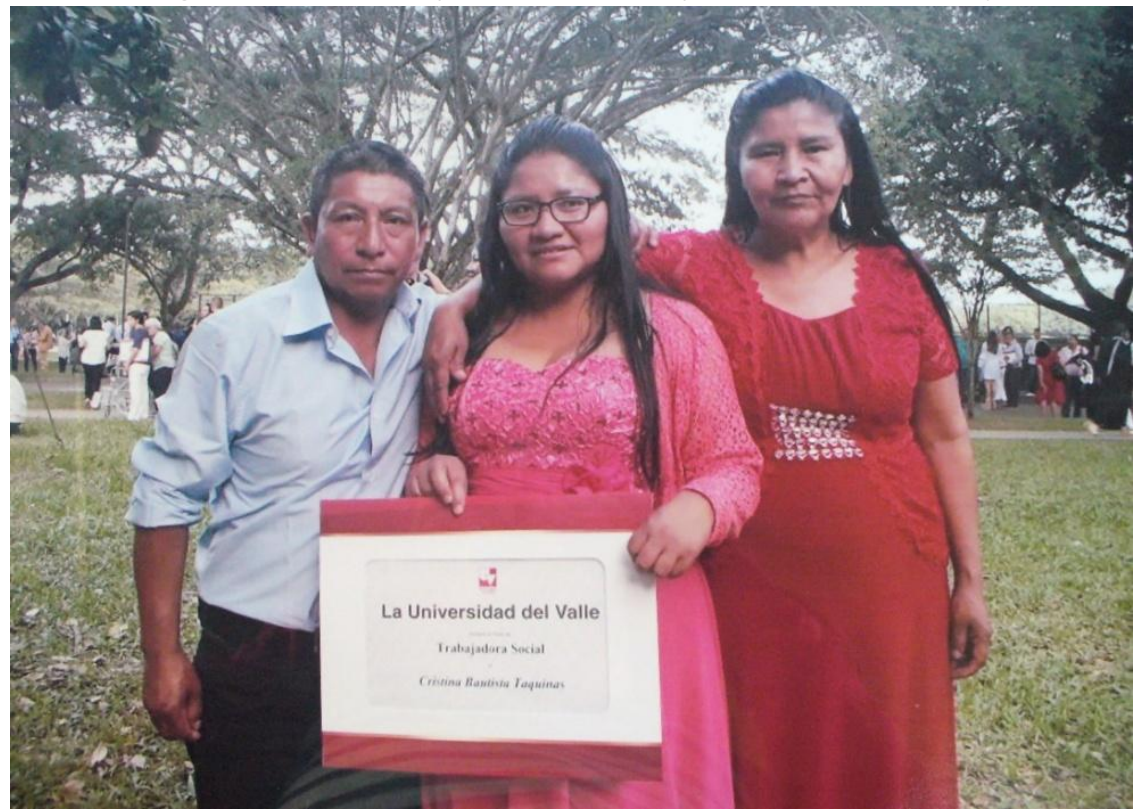

Fuente: álbum familiar

\section{Hilando pensamiento... entrelazar fuerzas para el movimiento de mujeres Nasa en Toribío}

Cristina siempre fue muy activa, quienes la conocieron de cerca dicen que no podía quedarse quieta, constantemente tenía ideas y proyectos en mente, le molestaba la lentitud con la que suelen transcurrir los procesos en los territorios, muchas veces constreñidos por 
Rodríguez-Pizarro y Betancourt-Maldonado

el marco institucional. No obstante, fue respetuosa de las dinámicas organizativas y sus canales formales; su interés era transformar desde adentro.

Una de sus principales preocupaciones al retornar a Toribío, después de graduarse como Trabajadora Social en el año 2018, eran las altas cifras de violencia contra las mujeres en el municipio. Por ello, convencida de que su deber era retribuir a su comunidad a través del trabajo con la gente, empezó a activar el proceso de mujeres, se encargó de reunir a distintas compañeras, algunas con trayectoria en la organización, otras nuevas en estas dinámicas; lo importante para ella, era que participaran mujeres de distintas veredas, que fueran jóvenes y que tuvieran ganas de trabajar a largo plazo. Le interesaba conocer y comprender cómo se manejaba el tema de las mujeres al interior de la organización indígena, sus fortalezas y debilidades.

Manifestaba a sus compañeras: "el movimiento de la mujer tiene que surgir y no puede ser tan lento", ella entendía la necesidad de poner este tema en primera línea dentro de las prioridades del Cabildo. Reconocía que las mujeres han estado históricamente en los procesos Nasa, no obstante, creía que era necesario dar un giro y posicionar el movimiento de las mujeres con autonomía, con demandas específicas y no relegado frente a otras líneas de trabajo de la organización.

(...) ella tenía unos sueños tan grandes, los sueños de ella no eran chiquitos (...) ella tenía claro que el proyecto de mujeres es trasversal a todos los programas que hay, y no solamente a la línea de familia como se había pensado comúnmente en la organización Nasa. (Yoli, integrante de Hilando pensamiento).

Empezar el movimiento de mujeres fue una lucha muy dura, al inicio lo veían como un problema, "nos decían las subversivas y nos trataban hasta mal" (Yoli, integrante de Hilando pensamiento). Para muchos hombres líderes, era molesto que las mujeres se organizaran y que en su base se encontraran jóvenes que cuestionaban lo que se estaba haciendo, y más bajo el liderazgo de Cristina, que era una mujer preparada académicamente y de mente muy abierta, con una importante proyección. Ella tenía como meta que Toribío fuera el centro del movimiento de mujeres a nivel departamental, con articulación nacional e internacional, siempre soñó en grande.

Cristina decía que la mujer necesita autonomía, que la mujer tiene que soñar, tiene que capacitarse, formarse y llegar a los espacios de decisión. (...) Ella pensaba en un pago justo a las mujeres, en que su trabajo debía ser valorado realmente y no desde el discurso, que tenía que reconocer lo que realmente vale el trabajo de la mujer. Porque la mujer en el campo también tiene doble jornada, trabaja la tierra, cuida los animales y también tiene que llegar a la casa a ocuparse de todo. (Yoli, integrante de Hilando pensamiento). 
Rodríguez-Pizarro y Betancourt-Maldonado

Hoy, Hilando Pensamiento es reconocido por las autoridades como un movimiento de mujeres cuyas acciones y propósitos se incluyen en el Plan de Vida Nasa. Pero al principio no fue fácil, las mujeres se reunían en una esquina, en un parque, a la intemperie, sin ningún tipo de logística o apoyo. Hacían recorridos por las veredas llevando las reflexiones sobre la autonomía de las mujeres y sus derechos, este trabajo no le gustaba mucho a los hombres y también era rechazado por algunas mujeres; pero Cristina estaba convencida que este era un proceso de educación a largo plazo. Para ella, la meta era llegar a las semillas de vida, es decir a las nuevas generaciones, trabajar en las escuelas, incidir en los procesos de crianza, para que los niños y las niñas no reprodujeranlos mismos patrones de relación actuales.

\section{Cuando la falda se viste de autoridad neehwe'sx}

$\mathrm{Al}$ inicio de su liderazgo, Cristina fue muy cuestionada e incluso fue objeto de burlas por ser mujer, por su juventud y por su filiación religiosa. Un proceso definitivo para ella como lideresa, fue participar en la Constituyente Nasa, allí, con perseverancia y humildad supo abrir camino, ganando un lugar legítimo. Cuando inició el proceso interno de Constituyente, ella solicitó cupos para participar como movimiento de mujeres; pero nunca obtuvo respuesta, entonces dijo a sus compañeras: "pues no nos invitaron, pero tampoco nos dijeron que no fuéramos" y decidió llegar al primer encuentro. En este espacio fue rechazada por algunas personas, principalmente hombres, quienes le manifestaron que, al no tener el aval formal, no había presupuesto para su alimentación y transporte; de nuevo, Cristina con su sabiduría y humildad, manifestó: "no vine a pelar ni por comida, ni por transporte, vine a aprender" (Yoli, integrante de Hilando pensamiento). Y siguió asistiendo a los encuentros por sus propios medios y llevando su comida. De a poco, con la perseverancia que la caracterizaba, fue ganando un lugar, hasta que su vozfue escuchada y terminó como una lideresa de ese proceso y como una de las redactoras de la Constituyente Nasa.

El proceso de la Constituyente la proyectó a mayor escala en su liderazgo, así, su nombre empezó a sonar para gobernadora; al principio no quería, su deseo era seguir estudiando y cursar una maestría, pero finalmente fue considerando lo que podría aportar a su comunidad y aceptó pasar a ocupar un lugar como autoridad Nasa, aunque siempre decía que ella estaba de paso. Llegó con legitimidad y una mayoritaria aceptación de parte de su comunidad, pero ella, mujer, joven, indígena y con convicciones religiosas férreas, seguía siendo resistida por algunos hombres que intentaban desdeñarla con burlas como "ahora que la faldura se va de neehwe'sxse acaba el movimiento". Para Cristina estas ofensas significaban un desafío de fortaleza, sabía que los cambios generan temores, los cuales enfrentó con su entrega al trabajo, su entereza, transparencia en su gestión y lealtad a sus convicciones. 
Rodríguez-Pizarro y Betancourt-Maldonado

Hoy es recordada con cariño y reconocimiento en su comunidad, en la Escuela de Trabajo Social y la Universidad del Valle. Admirada por su entrega al trabajo y por su honestidad, sus palabras aún vibran en el territorio y son inspiraciónpara las mujeres del Movimiento Hilando Pensamiento, que quieren continuar su legado en honor a su memoria y en resistencia al asesinato y la impunidad.

\section{Referencias bibliográficas}

Bautista-Taquinas, C., y Hernández-Mestizo, D.G. (2018). Percepción de mujeres y hombres en la implementación de la ley de víctimas y restitución de tierras 1448 y decreto étnico 4633 de 2011 en el hecho de homicidio en Toribio (resguardo de Tacueyó, Toribio y San Francisco) 2003 - 2018. (Tesis de pregrado). Universidad del Valle. Cali, Colombia.

DesInformémonos. (5 de noviembre de 2019). ¿Quién está matando indígenas y degollando civiles en el Cauca?DesInformémonos.org. Recuperado de https:/ / desinformemonos.org/quien-esta-matando-indigenas-y-degollando-civilesen-el-cauca/.

Semana. (2 de noviembre de 2019). La barbarie se ensaña contra los nasas. Semana.com. Recuperado de https://www.semana.com/nacion/articulo/barbarie-criminal-seensana-contra-los-nasas-en-cauca-que-esta-pasando/638853.

La verdad nada más que la verdad. (2019, noviembre 1). Cristina Taquinas Bautista último discurso [si callamosnos matan si hablamos también] [Archivo de video]. Recuperado de https:/ / www.youtube.com/watch?v=xY0OdRDd_Vo. 


\section{OTROS ARTÍCULOS DE PROSPECTIVA No. 30 DE 2020}

\section{EDITORIAL}

Coherencia, integridad y vida cotidiana

Luz Mary Sánchez-Rengifo

\section{ARTÍCULOS}

Trabajo Social y medios de comunicación: perspectivas y posibilidades de encuentro Social

Mercedes Muriel-Saiz

Maribel Martín-Estalayo

Seguridad, afectos y familias. Obstáculos en el proceso de reintegración de personas desmovilizadas de grupos

armados en Santander, Colombia

Jakeline Vargas-Parra

Ángela María Díaz-Pérez

Priscyll Anctil-Avoine

Reflexividad sobre la intervención profesional en duelo con población afectada por el conflicto armado en Colombia

María Cénide Escobar-Serrano

Maritza Charry-Higuera

Natalia Ramírez-Moncada

Ser mujer indígena, náhuatl, casada, migrante, sin trabajo remunerado: una realidad en los albergues jornaleros agrícolas en Colima, México

Nancy Elizabeth Molina-Rodríguez

Tipos y manifestaciones de la violencia de género: una visibilización a partir de relatos de mujeres víctimas en Soacha, Colombia

Diana Carolina Tibaná-Ríos

Diana Alejandra Arciniegas-Ramírez

Ingrid Julieth Delgado-Hernández

Análisis de necesidades en familias monoparentales con jefatura femenina usuarias de servicios sociales de atención primaria en España

Celia María Fernández-Martínez

Manuela Avilés-Hernández

Experiencias de intervención de trabajadoras sociales con trabajadores sexuales masculinos en Bogotá, Colombia Johan Arturo Barrera-Castellanos
Condiciones laborales de trabajadores sociales en hospitales públicos en la provincia de Mendoza,

Argentina

Cecilia Amalia Molina

Yanina Noemi Roslan-Angeloni

Analía Graciela Correa

Viviana Elena Varela

Gubernamentalidad neoliberal: miradas desde las intervenciones del Trabajo Social en el Gran La Plata, Argentina

Paula Mara Danel

Marcela Claudia Velurtas

Agustina María Favero-Avico

Educación superior en Trabajo Social en Chile y formación para la intervención en situación de calle. Desafios desde la evaluación que interventores hacen de sus procesos de práctica pre-profesional

Carlos Alejandro Andrade-Guzmán

Ignacio Andrés Eissmann-Araya

Educación en Derechos Humanos para el Trabajo Social en Chile: una mirada desde los estándares

internacionales

Lury Soledad Reyes-Pérez

Vivianne Soledad Hasse-Riquelme

Luis Marcelo Silva-Burgos

Arriesgar y preservar la vida: derechos humanos, conflicto sociopolítico armado y Trabajo Social en Colombia

Cristian Sebastián Castaño-Orozco

Ricardo Patiño-Martínez

\section{IN MEMORIAM}

Cristina Bautista Taquinás. Mujer indígena Nasa, Trabajadora Social, lideresa del norte del Cauca, Colombia

Alba Nubia Rodríguez-Pizarro

Lady Johanna Betancourt-Maldonado
ARTISTA INVITADO
MALA JUNTA KLAN
Alejandra Gutiérrez-Cárdenas

\section{PROSPECTIVA}

